\title{
Quality of Life and Psychiatric Symptoms in Wilson's Disease: the Relevance of Bipolar Disorders
}

\author{
M.G. Carta ${ }^{1, *}$, G. Mura ${ }^{1}$, O. Sorbello ${ }^{2}$, G. Farina ${ }^{1}$ and L. Demelia ${ }^{2}$ \\ ${ }^{I}$ Centro di Psichiatria di Consultazione e Psicosomatica, University Hospital Cagliari, Italy \\ ${ }^{2}$ UOC Gastroenterologia, AOU Cagliari, University Hospital Cagliari, Italy
}

\begin{abstract}
Introduction: Wilson's disease is an inherited disorder caused by a gene located on chromosome 13, which involved copper transportation across cell membranes. The disease can cause a reduced incorporation of copper into ceruloplasmin resulting in accumulation of this metal in the liver, central nervous system, kidneys and other organs. The objective is to define the frequencies of psychiatric disorders in WD, the amount of impairment of Quality of Life [QoL] in patients with WD and the relevance of the psychiatric disorders in the QoL of people suffering by WD.

Methods: This is a systematic review. The search of the significant articles was carried out in PubMed using specific key words.

Results: Such other neurological diseases, WD is characterized by chronic course and need of treatments, impairment of functional outcomes and high frequency of psychiatric symptoms, although a specific association between Bipolar Disorders and WD was recently found. Despite this, since today few studies are carried on WD patients' quality of life related to psychiatric symptoms. Some new reports showed a link between presence of Bipolar Disorders diagnosis, cerebral damage and low Qol.

Conclusion: Prospective studies on large cohorts are required to establish the effective impact of psychiatric disorders comorbidity, particularly Bipolar Disorders, on quality of life in WD and to clarify the causal link between brain damage, psychiatric disorders and worsening of QoL.
\end{abstract}

Keywords: Wilson's disease, psychiatric symptoms, quality of life, bipolar disorders, copper.

\section{INTRODUCTION}

Wilson's disease is an autosomal recessive inherited disorder of copper metabolism [1], caused by different mutations in a gene located on chromosome $13[2,3]$, which encodes the ATP 7B, an adenosine triphosphatase, involved in copper transportation across cell membranes [4]. There are over 200 mutations $[5,6]$ of the gene that can cause a reduced incorporation of copper into ceruloplasmin and a lower biliary excretion of copper, resulting in the accumulation of this metal in the liver, central nervous system, kidneys and other organs $[7,8]$.

The prevalence of WD in almost all ethnic groups is approximately $1: 30,000$ and the carriers are 1:90 [9]. WD is more frequent in communities isolated and characterized by a high consanguinity. In particular, in Sardinia [Italy] an incidence of 1/7.000 births has been found [10].

The age at presentation is mainly the pediatric age, usually between 6 and 8 years [11], but it's not infrequent to find clinical onset in adolescence and in young adults, however an onset above 40 years is rare [12].

*Address correspondence to this author at the Centro di Psichiatria di Consultazione e Psicosomatica, University Hospital, Cagliari, Italy;

Tel/Fax: +390706093498; E-mail: mgcarta@tiscali.it
The clinical manifestations of WD are the result of the gradual accumulation of free copper in the tissues, which may cause damage in many organs. Early manifestations are hepatic $[40 \%$ of cases], neurological [35\%], psychiatric [10\%] or other, such as hematologic, renal, ocular [15\%] [13]. Most WD patients present signs of liver and central nervous system involvement. Indeed, the majority of patients with WD present with either predominantly hepatic or neuropsychiatric symptoms, with either clinically asymptomatic or symptomatic liver involvement. The remaining $15-20 \%$ patients present with symptoms attributable to the involvement of other organs [14-16].

Patients with hepatic WD usually present in late childhood or adolescence, and exhibit features of acute hepatitis, fulminant hepatic failure, or progressive chronic liver disease in the form of either chronic active hepatitis or cirrhosis of the macronodular type $[17,18]$. The degree of liver involvement is variable, ranging from asymptomatic hepatosplenomegaly with mild elevations of certain liver enzymes, to complete liver failure. Associated symptoms include non specific general symptoms, ascites and jaundice, and symptoms such as hematemesis and melena that are caused by portal hypertension. Independently of the initial presentation, all WD patients will show abnormalities on liver biopsy [19]. A progression in hepatocellular carcinoma in these patients is rare [20]. 
In suspected cases of hepatic WD, if the clinical and biochemical parameters are not supportive, a hepatic biopsy can be carried out and a measure of its copper content obtained by mass spectroscopy or atomic absorption spectroscopy. Normal values are up to $250 \mu \mathrm{g}$ [microgram] per gram of dry tissue weight, and in WD this value is exceeded in about $80 \%$ of cases. Following biopsy, histochemical testing with rhodamine can also show copper and copper-associated protein, but their absence does not exclude a diagnosis of WD, particularly in children.

Kayser-Fleischer rings represent deposition of copper in Descemet's membrane of the cornea. When they are visible by direct inspection, they appear as a band of goldenbrownish pigment near the limbus. A slit-lamp examination by an experienced observer is required to identify KayserFleischer rings in most patients. They are not entirely specific for WD, because they may be found in patientswith chronic cholestatic diseases and in children with neonatal cholestasis; however, these disorders can usually be distinguished from WD on clinical ground. Kayser-Fleischer rings are present in only $44 \%-62 \%$ of patients with mainly hepatic disease at the time of diagnosis In children presenting with liver disease, Kayser-Fleischer rings are usually absent. However, Kayser-Fleischer rings are almost invariably present in patients with a neurological presentation, but even in these patients they may be absent in $5 \%$ of cases $[21,22]$.

Sunflower cataracts can be found in patients with Wilson's disease and these ocular abnormalities may resolve with chelation therapy.

It is possible the detection of hemolytic anemia that predisposes to cholelithiasis and may also represent the first presentation [23], and it is probably related to the release of large amounts of copper from damaged hepatocytes.

There may be manifestations of Fanconi syndrome and progressive renal failure with alterations of tubular transport of amino acids, glucose and uric acid.

Unusual manifestations include cardiomyopathy, arthritis and endocrinopathies, such as hypoparathyroidism [24].

Neurological symptoms occur later, mainly in adolescents and young adults [9].

The most common manifestations include postural and intentional tremors, dysphagia and contractions of facial muscles, dysarthria, bradykinesia, muscle hypertonia, choreo-athetosic movement of limb [25]. Imaging (CT, MRI, SPECT) shows unspecific changes in the basal ganglia, thalamus, cerebellum, brainstem and white matter [26].

Half of patients with neurological manifestations have a history of behavioral abnormalities in the five years prior to diagnosis. The clinical features are various and may include loss of emotional control [angry outbursts and bouts of crying], depression, hyperactivity, loss of sexual inhibitions, anxiety disorders, cognitive impairment, mental retardation, mania, behavioral abnormalities, personality changes and alcohol abuse [27]. These psychiatric symptoms can be the effects of brain tissues damage caused by copper accumulation, but might be also the consequence of a real comorbidity with affective disorders, bipolar disorder princi- pally, which might co-segregate with the mutation causing the WD in closed community with high consanguinity. Psychiatric symptoms with late insurgence may be side effects of treatments used to control WD core symptoms. For example, treatment with D-penicillamine was proved to cause neurological exacerbation or the occurrence of neuropsychiatric manifestations, particularly movement disorders, seizures and psychosis. Sometime these events may be irreversible, and can occur even in previously asymptomatic patients $[28,29]$. Whatever their origin, psychiatric symptoms further complicate the course of the disorder, since anxiety and depression negatively impact on quality of life and undermine the close compliance needed to achieve illness compensation; emotional and behavioral dyscontrol further and negatively impact on the social life of these patients, worsening the impairment and the disability caused by WD core symptoms.

Patient-reported point of view on health-related quality of life has become an interesting way to obtain information on the experience of disease, treatment efficacy and need of cares, as it reflects the individual's way to cope up with the illness.

Quality of life is a subjective, heterogeneous concept of wellbeing correlated with a number of factors, such as severity and duration of illness, use of medications and stress events. QoL has been defined to generally correspond to the total wellbeing and encompasses both the physical and the psychological determinants such as emotional wellbeing, behavioral competence, sleep and rest, energy and vitality and general life satisfaction [30]. The subjective perception of quality of life is a construct today considered of great relevance as a measure of outcomes in chronic disease [31, 32], particularly in those disorders that required long-term treatments and have great impairment and impact of daily life, and it has became central to evaluating the effectiveness of treatments in clinical research $[33,34]$.

Neurological diseases are often characterized by chronic course and impairment of functional outcomes, so measurement of QoL in paradigmatic neurological diseases appears today very interesting for well understanding the burden of illness tolerated by patients. In literature there are several studies on QoL in multiple sclerosis and Parkinson's disease, which show the correlation between a single symptom [i.e. fatigue, pain, movement impairment] or symptoms cluster, or impact of treatments and QoL. There is not a systematic review of studies on QoL in WD.

This paper sets out to review studies on the prevalence of psychiatric symptoms in patients with WD, aiming at defining the associated impact on the quality of life in patients with WD, to determine the relevance of these symptoms and their consequences on the life of people diagnosed with WD.

Past reviews on the topic often did not consider issues in validity and reliability of the tools used in psychiatric assessment, or included studies that did not use standardized criteria for the diagnosis of WD. This systematic review aimed at identifying high quality papers, based on valid and reliable measures of quality of life and based on standardized criteria for the diagnosis of WD. 


\section{METHODS}

The search of the significant articles was carried out in PubMed/Medline with the following key words: "Psychiatric symptoms and Wilson's disease"; "Depression and Wilson's disease"; "Depressive Disorder and Wilson's disease"; "Mood Disorders and Wilson's disease"; "Anxiety Disorders and Wilson's disease"; "Schizophrenia and Wilson's disease" and "Quality of life and Wilson's disease".

Interval was set from January 1981 To December 2011, and the search was further refined on 31 January 2012.

Over $400[n=452]$ papers were retrieved by the search. The abstract of the extracted papers were read and the more pertinent ones $[\mathrm{n}=115]$ were obtained in full version and analyzed in deep.

Data on quality of life were searched with the following key words: "Quality of Life" and "Wilson's disease". Overall, 15 studies were found available on the argument of "general well-being", but only 3 published papers and one already presented at congress and currently submitted for publication in a peer review journal were focused on the assessment of health-related QoL.

\section{RESULTS}

\subsection{Psychiatric Symptoms in WD}

The psychiatric manifestations of WD have been frequently reported, since the original paper of S.A.K Wilson, who described psychiatric symptoms in 8 out of his 12 cases, 2 of them with schizophrenia-like psychosis. [35, 36]. Psychiatric symptoms may be the symptom of presentation of the disease. According to case series, one third of patients with WD may initially present behavioral abnormalities, and failure to recognize these may lead to misdiagnosis and delay in starting specific treatment [37]. Currently, nearly $20 \%$ of patients undergo psychiatric treatment before specific chelation therapy begins [38].

A wide set of psychiatric, psychological and psychosocial impairments have been reported; these include: mental retardation [39], confusional states [40], cognitive impairment [41], dementia [42], poor school performance [43], anxiety [44], depression [45], emotional lability [46], mania, abnormalities of behavior and personality disorders [47], schizophrenia-like states [48, 49], suicide [25]. The frequency and relative clinical significance of different psychiatric manifestations are difficult to determine from the literature; while the possible association with schizophrenia-like states has attracted much interest, debate such states are infrequent, the exact lifetime prevalence of psychiatric symptoms in patients with WD is unclear but the estimates range is from 30 to $100 \%$ of symptomatic patient [49].

The psychiatric manifestation in WD have categorized into five clusters [49]: 1) cognitive impairment; 2) personality disorders; 3) affective disorders; 4) psychosis; 5) other psychiatric alterations.

\subsubsection{Cognitive Impairment}

Cognitive impairment occurs in less than $25 \%$ of patients $[25,36]$ and it is generally mild [44]. However, cognitive impairment worsens with progression of disease and the concomitance of neurological disorders [50]. A clear dementia is less common, and impairment of consciousness occurs almost always in terminal stages of disease [27]. The exact mechanisms by which this deficit is established remain unclear. Some authors related these changes to a reduce speed of the motor component rather than a slowing of information processing [51]. Others have suggested that abnormalities on neuropsychological tests in WD patients are due to a subclinical hepatic encephalopathy [52].

\subsubsection{Personality Disorders}

Lifetime prevalence of personality changes ranges from $46 \%$ to $71 \%[53,26]$, and typical symptoms are irritability or aggressiveness $[25,26]$. These symptoms have been correlated with the presence of dyskinesia, dysarthria and lesions of putamen and pallidum [54].

Irritability and aggression are often related to the displaying of incongruous behavior and personality changes [27]. Typically, incongruous behavior results from a dissociation between environmental cues and behavioral outcome, and expresses with disinhibited, bizarre and reckless behaviors.

\subsubsection{Mood Disorders}

Depression is an extremely common psychiatric problem in WD patients. Estimated prevalence of depression ranges 30 to $60 \%$ of cases, but its presence in patients with WD is underestimated [49].

Whether depression is a psychological reaction to WD or is due to biological impairment is unresolved. The situational aspects of living with a debilitating illness can give rise to demoralization, hopelessness, loss of self-worth, and expression of a wish to die. This fact is intuitively obvious to clinicians, patients, and families, and sometimes leads clinicians prematurely to assign a reactive explanation to the patient's symptoms [55]. In vivo neuroimaging studies suggest that depression and other neuropsychiatric disorders are associated with central serotonergic deficits. In a prospective study [38] on 23 adult patients with WD was revealed that depressive symptomatology (assessed using the Hamilton rating scale for depression (HAMD)) is related to an alteration of presynaptic serotonin transporters (SERT) availability as measured by (123I)-2beta-carbomethoxy-3beta-(iodophenyl)tropane ((123I) beta-CIT) and high-resolution single-photon emission computed tomography (SPECT). Data were correlated with the presynaptic serotonin transporter density (SERT density) in the thalamus-hypothalamus and the midbrain-pons regions measured with high-resolution single-photon emission computed tomography (SPECT). A significant negative correlation was found between HAMD and SERT density in the thalamus-hypothalamus region $(\mathrm{r}=-0.49, \mathrm{p}=0.02)$, but not in the midbrain-pons $(\mathrm{r}=-0.31, \mathrm{p}=0.15)$.

Overall, the prevalence of depression is higher in WD patients than in patients with other chronic disabling diseases, such as rheumatic arthritis, even with a similar level of disability [56]. This finding suggests that some biological component, probably the effect of brain tissues damage, is in cause in the production of symptoms of expression in patients with WD. The high prevalence of depression in WD is generally thought associates to a high risk of suicide. Suicidal behavior occurs from $4 \%$ to $16 \%$ of patients with WD 
across studies [25, 49]. A correlation between the degree of disability and the presence of depression is not yet established.

Other affective disorders, such as hypomania and mania, have also been reported in WD.

There are few case-reports in the literature of typical $\mathrm{Bi}$ polar Disorder as presenting symptom of WD [47, 57-61].

Costa Machado and colleagues [62] suggested a higher association between Bipolar Disorder and WD than previously reported in the literature. In their case series, which describes the neurological manifestations of 119 patients with WD, the authors observed a wide array of psychiatric symptoms: catatonia, agitation, aggression, delusional thoughts, and mania. In a study involved 50 confirmed patients with Wilson's disease [63], evaluation of the psychiatric co-morbidity was assessed by structured clinical interview for DSM-IV Axis-I disorders (SCID): 12 patients (24\%) fulfilled the diagnostic criteria for syndromic psychiatric diagnosis: Bipolar Disorder (18\%), Major Depressive Disorder (4\%), and dysthymia (2\%). Recently a study was carried out by our group [64] using a case-control desing with cases randomly selected from a community survey [64] to determine the association between neurological damage and mood disorders. Psychiatric diagnoses according to DSM-IV criteria were determined with structured interview tools (ANTAS-SCID) $[65,66]$ and brain damage was detected using SPECT to observe focal or diffuse decrease of uptake in grey matter. The results indicated that the lifetime prevalence of DSM-IV Bipolar and Major Depressive Disorders is higher in people with WD than in sex- and agematched controls. The OR was 12.9 for Bipolar Disorders and 6.7 for Major Depressive Disorders, and there was an association between SPECT positivity and Bipolar Disorders.

\subsubsection{Bipolar Disorder and Trace Elements Accumulation}

It is interesting to consider that it was hypothesized for the mood disorders a pathogenic mechanism involving trace elements accumulation.

In the literature, early studies showed that women affected by chronic depression sometimes have copper, zinc, and cesium deficiencies $[67,68]$, while later studies suggest that the presence of depression and other neuropsychiatric symptoms is due to the deposit of copper in the Central Nervous System [69]. In a study of 2003 [38] it was demonstrated, by SPECT, a reduction in thalamic and hypothalamic presynaptic dopamine and serotonin transporter due to the accumulation of copper. It was also highlighted a negative correlation between the density of presynaptic dopamine transporters and the severity of depression, assessed using the Hamilton Rating Scale for Depression. Another study [70] had hypothesized trace elements to be implicated as a causative factor for Bipolar mood Disorders, through a neurodegenerative mechanism of pathogenesis, while elevated vanadium and molybdenum levels have been reported in serum samples from Bipolar Disorders patients. This latter study showed, using DSM-IV standard diagnostic criteria and classification of Bipolar Disorders into types I, II, and V according to the concept of Young and Klerman, that Na, K, $\mathrm{P}, \mathrm{Cu}, \mathrm{Al}$, and $\mathrm{Mn}$ were elevated significantly in Bipolar I [Mania] $[\mathrm{P}<0.001]$. In Bipolar II-Hypomania, Na, S, Al, and
Mn were increased significantly $[\mathrm{P}<0.02]$, while in Bipolar II-Depression, $\mathrm{Na}, \mathrm{K}, \mathrm{Cu}$, and $\mathrm{Al}$ were increased significantly $[\mathrm{P}<0.001]$. Finally, in Bipolar $\mathrm{V}, \mathrm{Na}, \mathrm{Mg}, \mathrm{P}, \mathrm{Cu}$, and $\mathrm{Al}$ were increased significantly $[\mathrm{P}<0.002]$ compared to a control group. A more recent study by Gonzales-Estecha and colleagues [71] found higher serum copper and zinc, blood lead and cadmium, and urine lead, cadmium, and thallium concentrations in patients diagnosed with Bipolar Disorders compared to a control group.

Moreover, accumulation of copper was shown related to oxidative stress: in bivalve species [72] and in skeletal muscle of broilers under heat stress, copper decreases as effects of dietary Selenium, Vitamin E and their combination, in parallel with increases of antioxidant defense [73]. In Humans accumulation of copper was associated with oxidative stress in allergic asthma patients, in which introduction of nutritional supplement therapy decreases both oxidative stress and copper plasma levels, improving immune response and pulmonary function [74]. Oxidative stress may determine damages in Central Nervous System. Brain, which contains large amounts of polysaturated fatty acids and possesses low antioxidant capacity, is particularly vulnerable [75]. Copper levels were found elevated in several brain areas in a degenerative disease as Niemann-Pick C [76], which was specifically indicated to be associated to Bipolar Disorders [77].

Altered oxidative stress parameters were found associated to the pathophysiology and therapeutics of Bipolar Disorders, including changes in the levels of enzymes superoxide dismutase [SOD], catalase [CAT] and thiobarbituric acid reactive substances [TBARS] [78]. The well-known stabilizing agent Lithium was shown able to reverse increased oxidative stress parameters in Bipolar Disorders by limiting the enzyme activity, potentially lowering hydrogen peroxide and hydroxyl radical formation [79, 80]. For instance, in valproate and lithium-treated rats were observed a decline in lipid peroxidation and an increase in CAT levels [81, 82].

If the results of our study are confirmed, and the hypothesis that accumulation of minerals such as copper plays an etiological role in psychiatric disorders through an increase of oxidative stress damage may also be confirmed, WD may serve as a pathogenic model of Bipolar Disorders.

\subsubsection{Psychosis and New Perspective on Bipolar Disorder}

Schizophrenia and other form of psychosis in WD have been reported but it is widely accepted that these conditions are not more frequent in patients with Wilson's disease than the general population $[27,25]$ and are more frequent $[8 \%]$ in patients with neurological involvement [83]. This correlation, however, can lead to errors in diagnosis because the presence of neurological manifestations in a patient with psychosis may be misinterpreted as the side effect of neuroleptic treatment.

The strong association between bipolar disorders and WD should be interpreted, keeping in mind the modification of the diagnostic criteria and the evolution of the concept of "Bipolar Spectrum Disorders" in the last few decades [84]. It seems likely that literature reports in the past of "schizophrenia-like psychosis" in WD were due to use of a different definition of schizophrenia compared to current psychiatric diagnostic criteria. In contrast, the association of WD and 
bipolar disorder may explain the frequent descriptions of "loss of emotional control, hyperactivity, or loss of sexual inhibition, irritability" reported in WD patients [85, 62].

\subsubsection{Other psychiatric disorders}

Other psychiatric disorders have been associated with WD, such as anxiety disorders, substance abuse, catatonia and anorexia; their prevalence in WD patients compared with general population is difficult to determine from the literature [48].

\subsection{Treatment of Psychiatric Disorders in WD}

Specific treatment of WD itself can improve psychiatric and behavioral manifestation, although most studies focus purely on neurological changes rather than on psychiatric changes [49].

Treatment with D-penicillamine can lead neurological exacerbation or the occurrence of neuropsychiatric manifestations, particularly movement disorders, seizures and psychosis. These events may be irreversible and can occur even in previously asymptomatic patients $[28,29]$.

Treatment with Tetrathiomolybdate was associated with excellent results both for neurological symptoms and for psychiatric ones [83].

Follow-up studies have shown that mood stabilizers are effective in the management of mood disorders. Neuroleptics must be avoided routinely as their use may lead to significant worsening of parkinsonian features, tardive dyskinesia or other extrapyramidal symptoms, allowing creating errors in the diagnosis and management of these patients [37].

Some reports have demonstrated the efficacy of clozapine [86], quetiapine [87] and olanzapine [88].

Lithium has proven useful in the management of maniacal symptoms in patients who did not respond to antipsychotics; moreover lithium, unlike other drugs, is not metabolized by the liver and does not cause weight gain. However it may cause a worsening of tremor. The efficacy and the riskbenefit of treatment with psychotropic drugs in patients with Wilson's disease remains to be determined.

Literature offers few and discordant data regarding the curative effects of orthotopic liver transplantation [OLT] under psychiatric aspects. It has been described both the curative effect of the transplant on neuropsychiatric symptoms [89] and the severe worsening of psychiatric illness [90]. From a recent study it was emerged an excellent prospective of resolution also of psychiatric symptoms accompanied by late-postoperative persistent improvement [91].

\subsection{Quality of Life in WD}

There are few studies on QoL in WD: 3 published papers out of 15 were specifically focused on the assessment of health-related QoL; we added a fourth study, recently presented in a congress.

Komal Kumar and coll. [92] published a study with a small sample of WD patients [30 patients] evaluated using Neurological Symptom Score [NSS] for clinical severity and WHO-BREF for QoL. Patients [M:F $=23: 7]$ had a mean age of $27.97 \pm 11.16$ years at evaluation and the mean duration of treatment of $9.2 \pm 6.4$ years. All four domains of WHOQoL-BREF [Physical, Psychological, Social and Environmental] correlated well with each other $[p<0.01]$, indicating that QoL domains are interlinked, giving a holistic view of health. Individuals with limited functional mobility and ability to interact within their environment and society will most likely perceive their QoL to be poor, with NSS inversely correlated with the Physical domain $[p<0.02]$, while the duration of treatment had a positive correlation with the Physical domain $[p<0.01]$. The Physical domain of the QoL assessment was the only domain affected by duration and severity of disease: the psychological, social and environmental domains of QoL did not relate to severity of disease or duration of symptoms. Nevertheless, the small sample size and study restrictions [patients with inability to respond to the questionnaire due to behavioral problems, low IQ or other disease related factors were excluded] don't consent to generalize the results.

Recently, Svetel et al. [93] carried on a cross-sectional study to identify clinical and demographic factors influencing health-related QoL in 60 treated, clinically stable patients with WD using a generic questionnaire, the Medical Outcomes Study Short-Form 36-Item Health Survey [SF-36]. The level of disability and grading of WD severity were assessed by the Global Assessment Scale for WD [GAS for WD]; cognitive impairment and depressive features were assessed respectively by the Mini Mental State Examination [MMSE] and the 21-item Hamilton Depression Rating Scale [HDRS]. Lower scores on the SF-36 domains were found in patients with neurological and psychiatric symptoms compared with those with a predominantly hepatic form of WD. Significant inverse correlations were obtained between the various SF-36 domains and the period of latency from the first symptoms/signs appearance and treatment initiation, MMSE and HDRS scores, and the level of disability and grading of WD multi-systemic manifestations assessed by the Global Assessment Scale for WD [GAS for WD].

Sutcliffe and colleagues [94] published a paper on longterm follow-up and quality of life data obtained prospectively for 24 patients who underwent liver transplantation between 1988 and 2000 for Wilson's disease associated with severe liver disease. In long-term survivors, quality of life was assessed using the 36-Item Short Form 36 Health Survey Questionnaire. After a median follow-up of 92 months, all survivors [22 patients] have satisfactory graft function [5year patient and graft survival, 87.5\%], with quality-of-life scores [assessed in $86 \%$ of survivors] comparable to ageand sex-matched controls from the general population.

The above cited case-control study [66] aimed also to evaluate the impairment of quality of life due to mood disorders in WD. The results indicated that there was an association between SPECT positivity, Bipolar Disorders, and low quality of life as measured using SF-12. However, the power of the study did not allow to clarify whether the bipolarity caused the low quality of life or whether this was a confounding factor due to the same etiology [brain damages due to the copper accumulation, as demonstrated by SPECT positivity] for bipolarity and low quality of life. 


\section{DISCUSSION}

Neurological diseases with high frequency, such as stroke, Multiple Sclerosis, Parkinson's and Alzheimer's disease, characterized by severe psychiatric symptoms, are being detected for QoL assessment in several studies [95, 96]. Although the typical presentation of WD involves severely hepatic and nervous systems, initial symptoms are variable, often characterized by a mild, psychological distress, and making an early diagnosis difficult. In spite of this clinical condition is rare, it results medically and socially requiring, as those patients which receive a diagnosis during childhood have to endure the burden of disease and chronic treatment or will need liver transplantation decades later. Moreover, early treatments are often critical, especially in patients with neurologic disorders.

The association between WD and Bipolar Disorders appears today more frequent than believed in the past, dues to the more specific diagnostic criteria allowing to include as Bipolar Disorders cases that early researchers defined "schizophrenia-like psychosis" or "behavioral abnormalities" [97]. Several recent studies hypothesized that Bipolar Disorders etiopathogenesis may be due to trace elements accumulation [such as copper] in brain tissues, causing neurodegeneration. WD etiopathogenesis is analogue, and if the hypothesis that minerals such as copper play an etiological role in psychiatric disorders may be confirmed, WD may serve as a pathogenic model of Bipolar Disorders. Furthermore, in a recent study [64] the presence of brain damages detected by SPECT in WD patients was associated with a higher prevalence of lifetime DSM-IV Major Depressive Disorder and Bipolar Disorders, and lower SF-12 scores than controls. Nevertheless, prospective studies on large cohorts are required to establish the effective impact of psychiatric disorders, particularly Bipolar Disorder comorbidity on quality of life in WD patients and to clarify the causal link between brain damage, psychiatric disorders and worsening of QoL.

\section{CONFLICT OF INTEREST}

The authors confirm that this article content has no conflicts of interest.

\section{ACKNOWLEDGEMENT}

Declared none.

\section{REFERENCES}

[1] Bearn AG. A genetical analysis of thirty families with Wilson's disease (hepatolenticular degeneration). Ann Hum Genet 1960; 24: 33-43.

[2] Frydman M, Bonné-Tamir B, Farrer LA, et al. Assignment of the gene for Wilson's disease to chromosome 13: linkage to the esterase D locus. Proc Natl Acad Sci USA 1985; 82(6): 1819-21.

[3] Chappuis P, Bost M, Misrahi M, Duclos-Vallée JC, Woimant F. Wilson disease: clinical and biological aspects. Ann Biol Clin (Paris) 2005; 63(5): 457-66.(Article in French)

[4] Tanzi RE, Petrukhin K, Chernov I, et al. The Wilson disease gene is a copper transporting ATPase with homology to the Menkes disease gene. Nat Genet 1993; 5(4): 344-50.

[5] Thomas GR, Roberts EA, Walshe JM, Cox DW. Haplotypes and mutation in Wilson disease. Am J Hum Genet 1995; 56(6): 1315-9.

[6] Wilson AM, Schlade-Bartusiak K, Tison JL, Macintyre G, Cox DW. A minigene approach for analysis of ATP7B splice variants in patients with Wilson disease. Biochimie 2009; 91(10): 1342-5.
[7] Scheinberg IH, Sternlieb I, Schilsky M, Stockert RJ. Penicillamine may detoxify copper in Wilson's disease. Lancet 1987; 2(8550): 95.

[8] (a) Ferenci P. Pathophysiology and clinical features of Wilson disease. Metab Brain Dis 2004; 19(3-4): 229-39. (b) Ala A, Walker AP, Ashkan K, Dooley JS, Schilsky ML. Wilson's disease. Lancet 2007; 369(9559): 397-408.

[9] El-Youssef M. Wilson disease. Mayo Clin Proc 2003; 78(9): 112636 .

[10] Loudianos G, Dessi V, Lovicu M, et al. Molecular characterization of Wilson disease in the Sardinian population--evidence of a founder effect. Hum Mutat 1999; 14(4): 294-303.

[11] Pilloni L, Coni P, Mancosu G, et al. Late onset Wilson's disease. Pathologica 2004; 96(3): 105-10. Italian

[12] Ferenci P, Członkowska A, Merle U, et al. Late-onset Wilson's disease. Gastroenterology 2007; 132(4): 1294-8.

[13] Benhamla T, Tirouche YD, Abaoub-Germain A, Theodore F. (The onset of psychiatric disorders and Wilson's disease). Encephale 2007; 33(6): 924-32.

[14] Hlubocka Z, Maracek Z, Linhart A, et al. Cardiac involvement in Wilson disease. J Inherit Metab Dis 2002; 25: 269-77.

[15] Weizman Z, Picard E, Barki Y, Moses S. Wilson's disease associated with pancreatitis. J Pediatr Gastroenterol Nutr 1988; 7: 931-3.

[16] Carpenter TO, Carnes DL Jr, Anast CS. Hypoparathyroidism in Wilson's disease. N Engl J Med 1983; 309: 873-7.

[17] Schilsky M, Tavill AS. Wilson disease. In: Schiff ER, Soreel MF, Maddy WC, Eds. Disease of the Liver. Philadelphia: Lippincott Williams \& Wilkins 2003; pp. 1169-86.

[18] Sherlock S, Dooley J. Wilson disease. In: Diseases of the Liver and Biliary System. $11^{\text {th }}$ ed. Oxford: Blackwell Science 2002; pp. 41322.

[19] Sternlieb I. Perspectives on Wilson's disease. Hepatology 1990; 12(5): 1234-9.

[20] Polio J, Enriquez RE, Chow A, Wood WM, Atterbury CE. Hepatocellular carcinoma in Wilson's disease. Case report and review of the literature. J Clin Gastroenterol 1989; 11(2): 220-4.

[21] Merle U, Schaefer M, Ferenci P, Stremmel W. Clinical presentation, diagnosis and long-term outcome of Wilson's disease: a cohort study. Gut 2007; 56: 115-20.

[22] Tauber J, Steinert RF. Pseudo-Kayser-Fleischer ring of the cornea associated with non-Wilsonian liver disease. A case report and literature review. Cornea 1993; 12: 74-7.

[23] Michel M, Lafaurie M, Noël V, et al. Hemolytic anemia disclosing Wilson's disease. Report of 2 cases. Rev Med Interne 2001; 22(3): 280-3.

[24] Brewer GJ. Neurologically presenting Wilson's disease: epidemiology, pathophysiology and treatment. CNS Drugs 2005; 19(3): 18592. Review.

[25] Oder W, Grimm G, Kollegger H, Ferenci P, Schneider B, Deecke L. Neurological and neuropsychiatric spectrum of Wilson's disease: a prospective study of 45 cases. J Neurol 1991; 238(5): 281-7.

[26] Giagheddu M, Tamburini G, Piga M, et al. Comparison of MRI, EEG, EPs and ECD-SPECT in Wilson's disease. Acta Neurol Scand 2001; 103(2): 71-81.

[27] Dening TR, Berrios GE. Wilson's disease. Psychiatric symptoms in 195 cases. Arch Gen Psychiatry 1989; 46(12): 1126-34.

[28] McDonald LV, Lake CR. Psychosis in an adolescent patient with Wilson's disease: effects of chelation therapy. Psychosom Med 1995; 57: 202-4.

[29] Glass JD, Reich SG, DeLong MR: Wilson's disease: development of neurological disease after beginning penicillamine therapy. Arch Neurol 1990; 47: 595-6.

[30] Angermeyer MC, Holzinger A, Carta MG, Schomerus G. Biogenetic explanations and public acceptance of mental illness: systematic review of population studies. Br J Psychiatry 2011; 199: 36772.

[31] Mantovani G, Astara G, Lampis B, et al. Evaluation by multidimensional instruments of heath-related quality of life of elderly cancer patients undergoing three different "psychosocial" treatment approaches. A randomized clinical trial. Support Care Cancer 1996; 4(2): 129-40.

[32] Carta MG, Hardoy MC, Pilu A, et al. Improving physical quality of life with group physical activity in the adjuntive treatment of major depressive disorder. Clin Pract Epidemiol Ment Health 2008; 26; 4(1): 1 . 
[33] Mantovani G, Astara G, Lampis B, et al. Impact of psychosocial intervention on the quality of life of elderly cancer patients. Psychooncology 1996; 5: 127-35.

[34] Carpiniello B, Piras A, Pariante CM, Carta MG, Rudas N. Psychiatric morbidity and family burden among parents of disabled children. Psychiatr Serv 1995; 46: 940-2.

[35] Wilson SAK. Progressive lenticular degeneration: a familiar nervous disease associated with cirrosis of the liver. Brain 1912; 34 : 295-509.

[36] Akil M, Schwartz JA, Dutchak D, Yuzbasiyan-Gurkan V, Brewer GJ. The psychiatric presentations of Wilson's disease. J Neuropsychiat Clin Neurosci 1991; 3(4): 377-82.

[37] Srinivas K, Sinha S, Taly AB, et al. Dominant psychiatric manifestations in Wilson's disease: a diagnostic and therapeutic challenge! J Neurol Sci 2008; 266(1-2): 104-8.

[38] Eggers B, Hermann W, Barthel H, Sabri O, Wagner A, Hesse S. The degree of depression in Hamilton rating scale is correlated with the density of presynaptic serotonin transporters in 23 patients with Wilson's disease. J Neurol 2003; 250(5): 576-80.

[39] Pierson H. Two types of Wilson's disease; hepato-lenticular degeneration; case reports. J Neuropathol Exp Neurol 1952; 11(1):19-33.

[40] Inose T. Psychiatric manifestations of organic brain disorders. Nihon Rinsho 1969; 27(9): 2194-6.

[41] Bornstein RA, McLean DR, Ho K. Neuropsychological and electrophysiological examination of a patient with Wilson's disease. Int J Neurosci 1985; 26(3-4): 239-47.

[42] Rosselli M, Lorenzana P, Rosselli A, Vergara I. Wilson's disease, a reversible dementia: case report. J Clin Exp Neuropsychol 1987; 9(4): 399-406.

[43] Lingam S, Wilson J, Nazer H, Mowat AP. Neurological abnormalities in Wilson's disease are reversible. Neuropediatrics 1987; 18(1): 11-2.

[44] Rathbun JK. Neuropsychological aspects of Wilson's disease. Int J Neurosci 1996; 85(3-4): 221-9.

[45] Hesse S, Barthel H, Hermann W, et al. Regional serotonin transporter availability and depression are correlated in Wilson's disease. J Neural Transm 2003; 110(8): 923-33.

[46] Keller R, Torta R, Lagget M, Crasto S, Bergamasco B. Psychiatric symptoms as late onset of Wilson's disease: neuroradiological findings, clinical features and treatment. Ital J Neurol Sci 1999; 20(1): 49-54.

[47] Costa Machado A, Deguti MM, Caixeta L, Spitz M, Lucato LT, Barbosa ER. Mania as the first manifestation of Wilson's disease. Bipolar Disord 2008; 10(3): 447-50.

[48] Saint-Lauren M. Schizophrenia and Wilson's disease. Can J Psychiatry $1992 ; 37(5): 358-60$

[49] Akil M, Brewer GJ. Psychiatric and behavioral abnormalities in Wilson's disease. Adv Neurol 1995; 65: 171-8. Review.

[50] Arendt G, Hefter H, Stremmel W, Strohmeyer G. The diagnostic value of multi-modality evoked potentials in Wilson's disease. Electromyogr Clin Neurophysiol 1994; 34(3): 137-48.

[51] Littman E, Medalia A, Senior G, Scheinberg IH. Rate of information processing in patients with Wilson's disease. J Neuropsychiatry Clin Neurosci 1995; 7(1): 68-71.

[52] Tarter RE, Switala J, Carra J, Edwards N, Van Thiel DH. Neuropsychological impairment associated with hepatolenticular degeneration (Wilson's disease) in the absence of overt encephalopathy. Int J Neurosci 1987; 37(1-2): 67-71.

[53] Brewer GJ, Yuzbasiyan-Gurkan V. Wilson disease. Medicine (Baltimore). $1992 ; 71(3): 139-64$. Review.

[54] Oder W, Prayer L, Grimm G, et al. Wilson's disease: evidence of subgroups derived from clinical findings and brain lesions. Neurology 1993; 43(1): 120-4.

[55] Rosenblatt A, Leroi I. Neuropsychiatry of huntington's disease and other basal ganglia disorders. Psychosomatics 2000; 41(1): 24-30.

[56] Ehmann TS, Beninger RJ, Gawel MJ, Riopelle RJ. Depressive symptoms in Parkinson's disease: a comparison with disabled control subjects. J Geriatr Psychiatry Neurol 1990; 3(1): 3-9.

[57] Kumar Chand P, Murthy P. Mania as a presenting symptom of Wilson's disease. Acta Neuropsychiatr 2006; 18 (1): 47-9.

[58] Aravind VK, Krishnaram VD, Neethiarau V, Srinivasan KG. Wilson's disease--a rare psychiatric presentation. J Indian Med Assoc 2009; 107(7): 456-7.

[59] Keller R, Torta R, Lagget M, Crasto S, Bergamasco B. Psychiatric symptoms as late onset of Wilson's disease: neuroradiological find- ings, clinical features and treatment. Ital J Neurol Sci 1999; 20(1): 49-54.

[60] McDonnell GV, Esmonde TF. A homesick student. Postgrad Med J 1999; 75(884): 375-8.

[61] Vale TC, Caramelli P, Teixeira AL. Long-term mood disorder antedating the diagnosis of Wilson's disease. Rev Bras Psiquiatr 2011; 33(1): 101-2.

[62] Costa Machado A, Chien HF, Mitiko Deguti M, et al. Neurological manifestations in Wilson's disease: Report of 119 cases. Mov Disord 2006; 21(12): 2192-6.

[63] Shanmugiah A, Sinha S, Taly AB, et al. Psychiatric manifestations in Wilson's disease: a cross-sectional analysis. J Neuropsychiatry Clin Neurosci 2008; 20(1): 81-5.

[64] Hardoy MC, Carta MG, Marci AR, et al. Exposure to aircraft noise and risk of psychiatric disorder: the Elmas survey. Soc Psychiatry Psychiatr Epidemiol 2005; 40(1): 24-6.

[65] Carta MG, Aguglia E, Bocchetta A, et al. The use of antidepressant drugs and the lifetime prevalence of major depressive disorders in italy. Clin Pract Epidemiol Ment Health 2010; 6: 94-100.

[66] Carta MG, Sorbello O, Moro MF, et al. Bipolar disorders and Wilson's disease. BMC Psychiatry 2012; 12(1): 52.

[67] Ali SA, Peet M, Ward NI. Blood levels of vanadium, caesium and other elements in depressive patients. J Affect Disord 1985; 9: 18791.

[68] Hansen CR, Jr, Malecha AM, Mackenzie TB, Kroll J. Copper and zinc deficiencies in association with depression and neurological findings. Biol Psychiatry 1983; 18: 395-401.

[69] Pfeil SA, Lynn DJ. Wilson's disease: copper unfettered. J Clin Gastroenterol 1999; 29(1): 22-31. Review

[70] Sathyanarayana Rao TS, Zecca L, Jagannatha Rao K. Tracemetals, neuromelanin and neurodegeneration: An interesting area for research. Indian J Psychiatry 2007; 49(3): 154-6.

[71] González-Estecha M, Trasobares EM, Tajima K, et al. Trace elements in bipolar disorder. J Trace Elem Med Biol 2011; 25 Suppl 1: S78-S83.

[72] Gomes T, Pereira CG, Cardoso C, Pinheiro JP, Cancio I, Bebianno MJ. Accumulation and toxicity of copper oxide nanoparticles in the digestive gland of Mytilus galloprovincialis. Aquat Toxicol 2012; 118-119C: 72-9.

[73] Ghazi Harsini S, Habibiyan M, Moeini MM, Abdolmohammadi AR. Nutritional supplement therapy improves oxidative stress, immune response, pulmonary function, and quality of life in allergic asthma patients: an open-label pilot study. Altern Med Rev 2012; 17(1): 42-56

[74] Guo CH, Liu PJ, Lin KP, Chen PC. Nutritional supplement therapy improves oxidative stress, immune response, pulmonary function, and quality of life in allergic asthma patients: an open-label pilot study. Altern Med Rev 2012; 17(1): 42-56.

[75] Andreazza AC, Kauer-Sant'Anna M, Frey BN, et al. Effects of mood stabilizers on DNA damage in an animal model of mania. J Psychiatry Neurosci 2008; 33: 516-24.

[76] Vázquez MC, Martínez P, Alvarez AR, González M, Zanlungo S. Increased copper levels in in vitro and in vivo models of NiemannPick C disease. Biometals 2012; 25(4): 777-86.

[77] Sullivan D, Walterfang M, Velakoulis D. Bipolar disorder and Niemann-Pick disease type C. Am J Psychiatry 2005; 162(5): 1021-2.

[78] Andreazza AC, Cassini C, Rosa AR, et al. Serum S100B and antioxidant enzymes in bipolar patients. J Psychiatr Res 2007; 41: 523-9.

[79] Machado-Vieira R, Andreazza AC, Viale CI, et al. Oxidative stress parameters in unmedicated and treated bipolar subjects during initial manic episode: a possible role for lithium antioxidant effects. Neurosci Lett 2007; 421: 33-6.

[80] Ranjekar PK, Mahadik SP, Hegde MV, et al. Decreased antioxidant enzymes and membrane essential polyunsaturated fatty acids in schizophrenic and bipolar mood disorder patients. Psychiatry Res 2003; 121: 109-22.

[81] Shao L, Young LT, Wang JF. Chronic treatment with mood stabilizers lithium and valproate prevents excitotoxicity by inhibiting oxidative stress in rat cerebral cortical cells. Biol Psychiatry 2005; 58: 879-84.

[82] Khairova R, Pawar R, Salvadore G, et al. Effects of lithium on oxidative stress parameters in healthy subjects. Mol Med Report 2012; 5(3): 680-2.

[83] Brewer GJ, Johnson V, Dick RD, Kluin KJ, Fink JK, Brunberg JA. Treatment of Wilson disease with ammonium tetrathiomolybdate. 
II. Initial therapy in 33 neurologically affected patients and followup with zinc therapy. Arch Neurol 1996; 53(10): 1017-25.

[84] Carta MG, Kovess V, Hardoy MC, et al. Psychosocial wellbeing and psychiatric care in the European Communities: analysis of macro indicators. Soc Psychiatry Psychiatr Epidemiol 2004; 39(11): 883-92.

[85] Guha SK, Modak D, Basu A, Bhattacharya RS. Coomb's Positive Autoimmune Haemolytic Anaemia in a Case of Wilson Disease: Co-incidence or Association? J Indian Acad Clin Med 2009; 10(1 \& 2): 78-80.

[86] Krim E, Barroso B. Psychiatric disorders treated with clozapine in a patient with Wilson's disease. Presse Med 2001; 30(15): 73.

[87] Kulaksizoglu IB, Polat A. Quetiapine for mania with Wilson's disease. Psychosomatics 2003; 44(5): 438-9.

[88] Chroni E, Lekka NP, Tsibri E, Economou A, Paschalis C. Acute, progressive akinetic-rigid syndrome induced by neuroleptics in a case of Wilson's disease. J Neuropsychiatry Clin Neurosci 2001; 13(4): 531-2.

[89] Schilsky ML, Scheinberg IH, Sternlieb I. Liver transplantation for Wilson's disease: indications and outcome. Hepatology 1994; 19(3): 583-7.

[90] Kassam N, Witt N, Kneteman N, Bain VG. Liver transplantation for neuropsychiatric Wilson disease. Can J Gastroenterol 1998; 12(1): $65-8$.
[91] Sorbello O, Riccio D, Sini M, et al. Resolved psychosis after liver transplantation in a patient with Wilson's disease. Case Report. Clin Pract Epidemiol Ment Health 2011; 7: 182-4.

[92] Komal Kumar RN, Taly AB, Nair KPS, et al. Quality of life in Wilson's disease. Ann Indian Acad Neurol 2008; 11(1): 37-40.

[93] Svetel M, Pekmezović T, Tomić A, et al. Quality of life in patients with treated and clinically stable Wilson's disease. Mov Disord 2011; 26(8): 1503-8.

[94] Sutcliffe RP, Maguire DD, Muiesan P. Liver transplantation for Wilson's disease: Long-term results and quality-of-life assessment. Transplantation 2003; 75: 1003-6.

[95] Mura G, Bhat KM, Pisano A, Licci G, Carta MG. Psychiatric symptoms and quality of life in systemic sclerosis. Clin Pract Epidemiol Ment Health 2012; 8: 30-5.

[96] Carta MG, Hardoy MC, Garofalo A, et al. Association of chronic hepatitis $\mathrm{C}$ with major depressive disorders: irrespective of interpheron-alpha therapy. Clin Pract Epidemiol Ment Health 2007; 3: 22.

[97] Carta MG, Angst J. Epidemiological and clinical aspects of bipolar disorders: controversies or a common need to redefine the aims and methodological aspects of surveys. Clin Pract Epidemiol Ment Health 2005; 1(1): 4.

(C) Carta et al.; Licensee Bentham Open.

This is an open access article licensed under the terms of the Creative Commons Attribution Non-Commercial License (http://creativecommons.org/licenses/by-nc/3.0/) which permits unrestricted, non-commercial use, distribution and reproduction in any medium, provided the work is properly cited. 